\title{
Influence of Indian Cedar Particle Pretreatments on Cement-wood Composite Properties
}

\author{
Carolina A. B. Oliveira, ${ }^{a}$ João V. F. Silva, ${ }^{a}$ Natália A. Bianchi, ${ }^{a}$ Cristiane I. Campos, ${ }^{\text {b }}$ \\ Karina A. Oliveira, ${ }^{\mathrm{a}, *}$ Danilo S. Galdino, ${ }^{\mathrm{a}}$ Marilia S. Bertolini, ${ }^{\mathrm{b}}$ Cesar A. G. Morais, ${ }^{\mathrm{b}}$ \\ Alexandre J. D. de Souza, ${ }^{b}$ and Julio C. Molina ${ }^{b}$
}

\begin{abstract}
This work physically, mechanically, and chemically characterized the composites produced from Portland CP II-E32 cement and fresh Indian cedar wood particles previously treated by immersion in hot and cold water. Density values for wood particulate composites were around $50 \%$ lower compared with the wood-free control treatment, from 0.88 to 1.78 $\mathrm{g} / \mathrm{cm}^{3}$. A larger swelling was observed for the composite material. The results of compressive strength and stiffness indicated that there is no need for particle treatment for composite production. Hot and cold water immersion treatments reduced the total Indian cedar wood extractives by $33 \%$ and $42 \%$, respectively. Optical microscopy analysis was used to identify adhesion failures between the cement/wood interface of the composite produced with fresh particles, which presented a higher percentage of extractives. This result indicated that the greater concentration of total extractives partially inhibits the matrix-matrix interaction reinforcement. Despite the reduction in total extractives caused by the treatments, this process is not necessary for the composite production because there is no statistical difference between the treatments. The values obtained for the composite indicate the possibility of application in sealing blocks in light construction systems.
\end{abstract}

Keywords: Wood panels; Lignocellulosic materials; Cementitious composite; Cedar wood

Contact information: a: Department of Mechanical Engineering, UNESP - São Paulo State University, Avenida Ariberto Pereira da Cunha, 333, Guaratinguetá/SP, Brazil; b: UNESP - São Paulo State

University, Campus of Itapeva, Rua Geraldo Alckmin, 519, Itapeva/SP, Brasil;

* Corresponding author: kari.oliveira@outlook.com

\section{INTRODUCTION}

Acrocarpus fraxinifolius Wight ex Arn., popularly known as Indian cedar, is a species of the Fabaceae family, native to tropical Asian regions such as India, Myanmar (Burma) and Bangladesh; it is a fast growing wood having a productivity between 30 and $45 \mathrm{~m}^{3} /$ ha.year (Prado et al. 2003). Brought to Brazil in the 1990s, the species adapted to Brazilian soil (Higa and Prado 1998) and has been indicated for reforestation in the northern regions of Paraná, the Southeast and the Midwest of Brazil (Carvalho 1998).

This wood is currently used for construction, furniture, and caskets (Prado et al. 2003). However, it is practically unknown in Brazil, and studies involving this species are still related to physical, chemical, and mechanical characterization (Venturin et al. 2014).

The production of cement-wood composite is a possible destination for Indian cedar wood, since the particles used in the production can be obtained from small diameter trees or waste disposed in the sawmills.

Due to the growing demand for environmentally friendly products, the use of waste 
in composite materials has increased and presents promising and attractive technology (Hamouda et al. 2019). Also, the use of alternative materials as building materials contributes to reducing environmental impact (Wang et al. 2016).

The wood cement composite has properties for use in construction, for applications in form of sealing blocks, slabs, slab and mortar fillers (Pimentel et al. 2006; Moslemi 1999), and as an alternative to replacement of asbestos fibers (Ashori et al. 2011; Bertolini et al. 2014; Silva et al. 2016, 2019).

With the incorporation of cement, plant residues previously vulnerable to biological degradation and environmental weather gain strength and durability (Naghizadeh et al. 2012; Faria et al. 2013), and the presence of air pores in wood-cement panels contributes to improve the thermal and acoustic insulation properties (Branco and Godinho 2013; Berardi and Iannace 2015; Wang et al. 2016).

One of the main difficulties in this industry is the selectivity of the wood species used (Moslemi and Pfister 1987; Castro and Iwakiri 2014). Theoretically, most lignocellulosic products can be used as raw material for the manufacture of mineral matrix composites (Latorraca and Iwakiri 2001). However, some chemical substances (phenolic compounds, acids, and sugars) present in wood may slow and in some cases prevent cement solidification due to incompatibility between the matrix and the dispersed phase, causing the use of certain species to eventually be limited (Del Menezzi et al. 2007; Ashori et al. 2011).

Reforestation wood species are widely used for this purpose, mainly coniferous woods, due to their more compatible chemical properties, which do not affect the cure and hardening of ceramic material (Latorraca and Iwakiri 2001). The use of previous treatments performed on wood represents a way to improve its compatibility with cement and enable the use of certain species that have high levels of extractives (Moslemi et al. 1983; Latorraca and Iwakiri 2000; Fan et al. 2012).

Treatment possibilities for wood particles include soaking in hot water for $6 \mathrm{~h}$, soaking in cold water for $24 \mathrm{~h}$, soaking in sodium or calcium hydroxide solution (Fan et al. 2012; Castro et al. 2014), immersion of magnesium chloride solution (Frybort et al. 2008), and mineralization through cement coating (Frybort et al. 2008; Garcez et al. 2016). Additionally, there exists the possibility of using the core-shell technique which involves coating with nanoparticles (Libor et al. 2009; Tessaro et al. 2015). The effectiveness of treatments can be analyzed by possible changes in the mechanical behavior of these composites (Fan et al. 2012).

In this work, the interaction between Portland cement and in natura Indian cedar wood particles treated by immersion in hot or cold water was analyzed by evaluating the effects of pretreatments on the physical, chemical, and mechanical properties of the composite.

\section{EXPERIMENTAL}

The wood species used in this research was the 9-year-old Indian cedar with a specific mass of $0.431 \mathrm{~g} / \mathrm{cm}^{3}$. This wood was chosen for this study because it's a fastgrowing specimen, widely available in the region of São Paulo-Brazil that still is little used in the country.

The wood was chopped using a knife chipper (Model 685/5, MARCONI) and reduced to particle size in a hammer mill (Model 680, MARCONI). The particles were 
classified by an electric stirrer with sieves of different openings. For the composite production the particles with thicknesses of 0.25 to $4 \mathrm{~mm}$ were used. The binder used was Cauê InterCement® Portland cement, type CP II E32 (São Paulo, Brazil).

\section{Wood Particle Treatment}

Two treatments were performed on the particles, according to the methodologies studied by Fan et al. (2012) and Castro et al. (2014), aiming at the removal of extractives that could inhibit cement curing: immersion in hot water and immersion in cold water.

For the pretreatment consisting of immersion in hot water, the particles were submerged in distilled water at $60{ }^{\circ} \mathrm{C}$ for $6 \mathrm{~h}$ using a thermal bath with 3 cycles of $2 \mathrm{~h}$, changing treatment water to wash the particles. In the pre-treatment with cold water immersion, the particles were submerged in cold distilled water for $24 \mathrm{~h}$, and the water was changed every $6 \mathrm{~h}$.

After pretreatment, the particles were washed in distilled water and dried in a laboratory oven at $103 \pm 2{ }^{\circ} \mathrm{C}$ for $24 \mathrm{~h}$, reaching a moisture content of $3 \%$. This drying was performed to homogenize the moisture of the particles, allowing the quantification of water necessary for cement hydration in the composite production.

\section{Production of Cement-Wood Composite}

The treatments to which the particles were subjected and the proportions of materials for the production of composites are expressed in Table 1.

Table 1. Experimental Plan

\begin{tabular}{|c|c|c|}
\hline Composite & Treatment & Cement : Wood : Water ratio \\
\hline T1 & Control sample (only cement and water) & $1.00: 0.00: 0.40$ \\
\hline T2 & Untreated wood particles & $1.00: 0.36: 0.75$ \\
\hline T3 & $60^{\circ} \mathrm{C}$ water for 6 hours & $1.00: 0.36: 0.75$ \\
\hline T4 & Cold water (room temperature) for 24 hours & $1.00: 0.36: 0.75$ \\
\hline
\end{tabular}

First, the water and cement were mixed until a homogeneous mass was obtained; then the wood particles were added. The particles were added later to avoid water absorption that would impair the homogenization of the composite.

For the axial compression test, the mixture was molded into a $50 \mathrm{~mm}$ diameter and $100 \mathrm{~mm}$ long PVC pipe (Fig. 1a). For the analysis of thickness swelling and optical microscopy, specimens of $50 \times 50 \times 10 \mathrm{~mm}$ were produced (Fig. 1b). The ABNT NBR 7215 (1996) standard was used as the basis for molding.
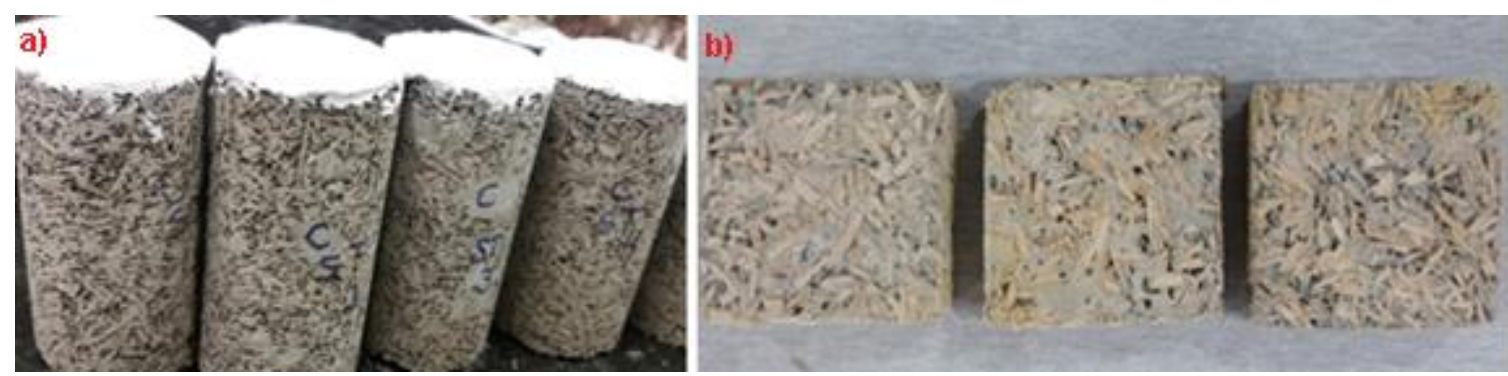

Fig. 1. Wood-cement composite for: axial compression test (a) and thickness swelling and optical microscopy test (b) 


\section{Characterization Tests}

The tests described below were performed in the laboratories of UNESP Itapeva, São Paulo, Brazil, after 28 days of drying of the composites, which is the period indicated by the manufacturer Cauê InterCement ${ }^{\circledR}$ for cement curing.

The compressive strength and axial stiffness test was performed according to the Brazilian standard ABNT NBR 7215 (1996), using the universal EMIC test machine with capacity of $300 \mathrm{kN}$. Axial compression is assessed by applying a pressure load to the axial cross-section of the specimen at a controlled speed of $0.25 \pm 0.05 \mathrm{MPa} / \mathrm{s}$. The strength value is the maximum value supported by the specimen and the stiffness is obtained by the stress $x$ strain curve generated by the machine software (TESC, Instron, Brazil).

The density and 24-h swelling tests were performed according to ABNT NBR 14810-2 (2018) standard. The density of the specimens was defined by Eq. 1, where $D$ is the density $\left(\mathrm{g} / \mathrm{cm}^{3}\right), M$ is the mass $(\mathrm{g})$ and $V$ is the volume $\left(\mathrm{cm}^{3}\right)$ of the specimen. To determine the 24-hours swelling, the specimens were measured and completely submerged in deionized water at $20{ }^{\circ} \mathrm{C}$ for $24 \mathrm{~h} \pm 36 \mathrm{~min}$. After the immersion period, the specimen was measured again. The swelling is calculated by Eq. 2, where $I$ is the swelling in specimen thickness $(\%), E_{1}$ is the thickness after immersion $(\mathrm{mm})$ and $E_{0}$ is the thickness before immersion $(\mathrm{mm})$.

$$
\begin{aligned}
& D=\frac{M}{V} \\
& I=\frac{E_{1}-E_{0}}{E_{0}} \times 100
\end{aligned}
$$

The extraction and determination of the content of hot and cold water soluble extractives and determination of the total extractives present in the fresh material were performed based on the TAPPI T204 cm-97 (1997) standard. For extraction, a Soxhlet extraction apparatus coupled to an extraction flask, a siphon, a Graham condenser, and a heating blanket were used. Three repetitions were performed for each composite.

For the optical microscopy analysis of the composites a magnifying glass with incident light and camera (model LEICA DFC295, Wetzlar, Germany) coupled to a computer with the software Leica QWin Standard (V 3.5.1, 2008) were used. Images were collected from the composites surface and along the thickness. Increases from $10 \mathrm{X}$ to $60 \mathrm{X}$ were used according to the need of the element being analyzed.

The obtained data was statistically analyzed by analysis of variance (ANOVA) and Tukey test to evaluate the effect of treatments and interactions at 5\% probability. The analysis was performed with the software R (R Core Team 2018, version 3.5.1).

\section{RESULTS AND DISCUSSION}

\section{Physical and Mechanical Properties of Composite}

Table 2 shows the values of density, strength, and stiffness due to axial compression, and the results of swelling analysis of specimen thickness for the four treatments studied. Standard deviation values are shown in parentheses, and variance analysis results are shown as letters. The density was significantly reduced with the incorporation of wood particles.

The values obtained for the composites were about $50 \%$ lower than those obtained by the control sample. The lower density of the composites occurred, consequently, due to 
the replacement of part of the cement volume by wood particles that have lower density.

Table 2. Density, Swelling, Strength, and Stiffness Values

\begin{tabular}{|c|c|c|c|c|}
\hline \multirow[b]{2}{*}{ Composite } & \multirow[b]{2}{*}{$\begin{array}{r}\text { Density } \\
\left(\mathrm{g} / \mathrm{cm}^{3}\right)\end{array}$} & \multirow[b]{2}{*}{$\begin{array}{l}\text { Swelling } \\
(\%)\end{array}$} & \multicolumn{2}{|c|}{ Axial Compression } \\
\hline & & & $\begin{array}{l}\text { Strength }\left(f_{c 0}\right) \\
(\mathrm{MPa})\end{array}$ & $\begin{array}{c}\text { Stiffness (Emo) } \\
(\mathrm{MPa})\end{array}$ \\
\hline $\mathrm{T} 1$ & $1.78(0.014)^{A}$ & $0.34(0.18)$ A & $17.74(2.14)^{A}$ & $1356.80(101)^{A}$ \\
\hline T2 & $0.88(0.012)^{\mathrm{C}}$ & $1.79(0.32)^{A}$ & $3.57(0.10)^{B}$ & $141.26(9)^{B}$ \\
\hline T3 & $0.93(0.004)^{B}$ & $1.31(0.33)^{A}$ & $3.68(0.17)^{\mathrm{B}}$ & $205.13(24)^{B}$ \\
\hline T4 & $0.85(0.009)^{C}$ & $2.23(0.71)^{A}$ & $3.53(0.11)^{B}$ & $252.84(7)^{\mathrm{B}}$ \\
\hline
\end{tabular}

The treatments influenced the density of the composite, and the composite made with the particles treated in hot water presented higher density and differed statistically from the other treatments.

The density values were lower than those obtained by Iwakiri and Prata (2008), who used the same trait of the present study, and obtained densities ranging from 1.05 to $1.17 \mathrm{~g} / \mathrm{cm}^{3}$. It is noteworthy that in the aforementioned study, particles of Eucalyptus grandis and Eucalyptus dunnii with densities of 0.64 and $0.69 \mathrm{~kg} / \mathrm{m}^{3}$ respectively according to Annex B of ABNT NBR 7190:1997 were used, which are higher than the density of the Indian Cedar wood used in this study.

The composite density values determined in this work were close to those obtained by Castro et al (2014), from 0.75 to $0.88 \mathrm{~g} / \mathrm{cm}^{3}$; the cited authors used Eucalyptus benthamii particles with a density of $0.47 \mathrm{~g} / \mathrm{cm}^{3}$. This value is close to the average density of cedar wood.

The average thickness swelling values after $24 \mathrm{~h}$ of water immersion obtained with the Indian cedar cement-wood composite were close to the 1.64 to $2.12 \%$ range obtained by Latorraca (2000) for cementitious composites produced with species of eucaliptus.

The Bison-Wood Cement Board process (1978) provides values between 1.2 to $1.8 \%$ after $24 \mathrm{~h}$ of soaking the composite in water. The composites produced with the fresh water treated particles met the stipulated values; however, the composite produced with the cold water treated particles exceeded the limit established by this process. Specimens produced with fresh particles and previously treated showed no statistically significant differences by Tukey test at 5\% significance, which can be justified by the high standard deviation observed in treatment $\mathrm{T} 4$.

Due to the reduction in density, the compressive strength and stiffness of the cement-wood composites were inferior to the control sample. The treatments had no influence on the variation of strength and stiffness in the axial compression of the composite. Therefore, the treatments studied to improve this property were not different.

\section{Composite Chemical Properties}

The solvents used in this study for the analysis of total extractives are capable of dissolving various types of water-insoluble lipophilic (resinous acids and fatty acids) and water-soluble extractives (salts, simple sugars, polysaccharides and some phenolic substances) (Sarto and Sansigolo 2010; Sheshmani et al. 2012).

The extraction and determination of the total extractives content showed a 
significant reduction of extractives between the fresh and previously treated particles, with a reduction of $42.4 \%$ by the cold water treatment and $33.8 \%$ by the hot water treatment (Table 3). Although pretreatments for extractives removal did not present statistically significant differences among them, the hot water (T2) treatment presented lower efficiency, and the same was observed by Castro et al. (2014).

Table 3. Total Extractive Values

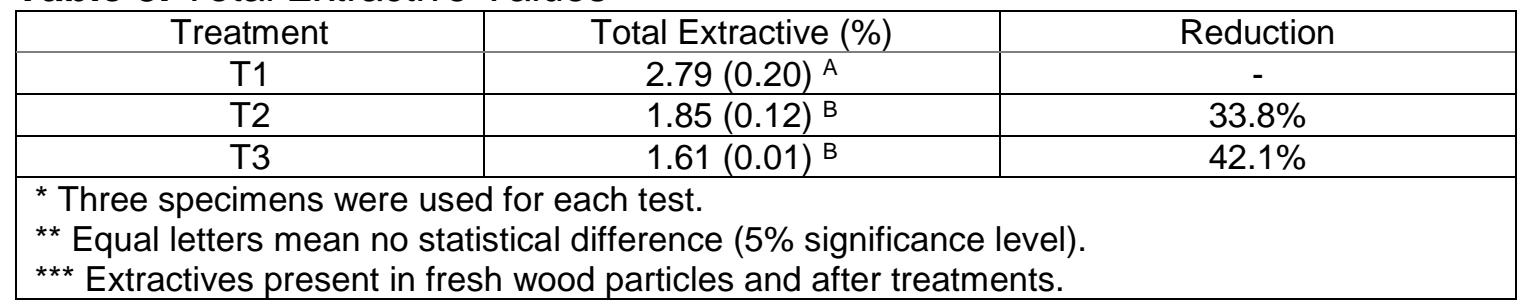

\section{Optical microscopy}

Figure 2 shows optical microscopy images of the surface between the cement and the wood particle of each composite produced. Figures $2 a, 2 b$, and $2 c$ shows the presence of voids after the treatments produced with fresh wood particles, treated in hot water, and cold water. Besides reducing the density of the composites, the voids facilitate the absorption of water and, consequently, its swelling. The voids indicated by the arrows in Figs. $2 \mathrm{a}, 2 \mathrm{~b}$, and $2 \mathrm{c}$ reduce the matrix-reinforcement interaction.
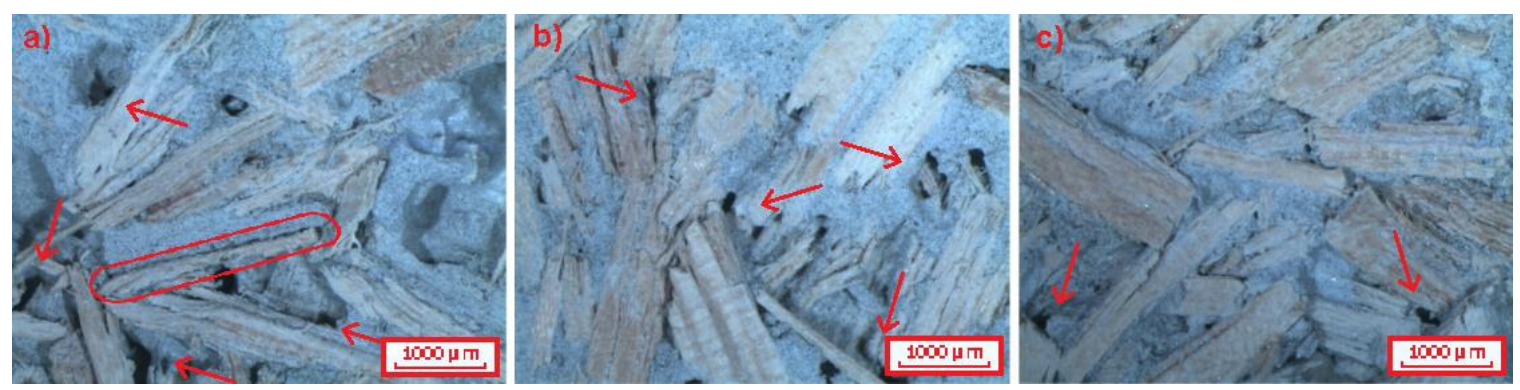

Fig. 2. 10X optical microscopy of a) T2, b) T3 and c) T4

Another issue observed is the presence of some adhesion failures at the interface between the cement and particles in the specimen produced with fresh particles, indicated by the circle in Fig. 2a. These adhesion failures can best be observed in the image obtained with 60X magnification (Fig. 3a). It is noteworthy that after the treatments, there was a better interaction between matrix and reinforcement (Figs. 3b and 3c).
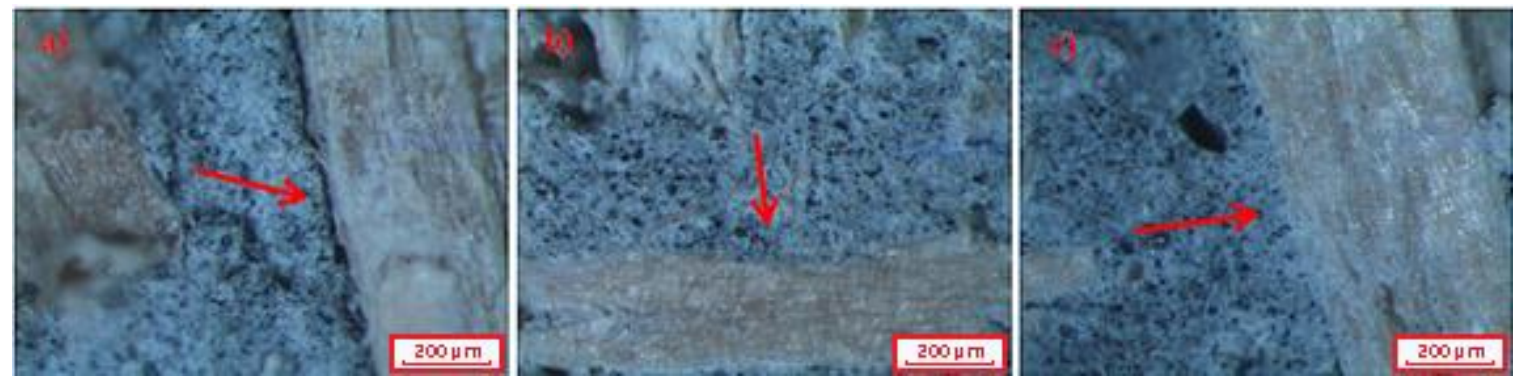

Fig. 3. 60X optical microscopy of a) T1, b) T2, c) T3, and d) T4 
According to Miller and Moslemi (1991), the extractives may migrate and concentrate on the wood surface during the composite cure, causing the formation of a hydrophobic layer that reduces the hydrogen bridges between cement and wood, causing adhesion failures that reduce the resistance at the interface.

\section{CONCLUSIONS}

1. The inclusion of wood particles at a ratio of 36 parts per 100 parts of cement solids halved the density value of the material studied compared with the control treatment.

2. The properties of swelling, strength, and stiffness to the axial compression of the composites were not influenced by the particles used, either fresh or treated.

3. Pre-treatment for the use of Indian cedar wood particles is not required for the manufacture of this composite.

4. The performance of the cement-wood composite presented values suitable for application in sealing blocks in lightweight construction systems, as the values obtained in the compression test showed similar results to materials with this commercial application.

\section{REFERENCES CITED}

ABNT NBR 7215 (1996). "Portland cement: Determination of compressive strength," Brazilian Technical Standards Association, Rio de Janeiro, Brazil.

ABNT NBR 7190 (1997). "Design of wooden structures," Brazilian Technical Standards Association, Rio de Janeiro, Brazil.

ABNT NBR 14810-2 (2018). "Medium density particle board. Part 2: Requirements and test methods," Brazilian Technical Standards Association, Rio de Janeiro, Brazil.

Ashori, A., Tabarsa, T., Azizi, K., and Mirzabeygi, R. (2011). "Wood-wool cement board using mixture of eucalypt and poplar," Industrial Crops and Products 34, 1146-1149. DOI: 10.1016/j.indcrop.2011.03.033

Berardi, U., and Iannace, G. (2015). "Acoustic characterization of natural fibers for sound absorption applications," Building and Environment 94(2), 840-852. DOI: https://doi.org/10.1016/j.buildenv.2015.05.029

Bertolini, M. S., Campos, C. I., Souza, A. M., Panzera, H. P., Christoforo, A. L., and Lahr, F. A. R. (2014). "Wood-cement composites from wastes of Pinus sp. wood: effect of particles treatment," International Journal of Composite Materials 4(2), 146-149. DOI: 10.5923/j.cmaterials.20140402.14

Bison Wood-Cement Board (1978). Production Process of Cement-wood Boards, Berlin.

Branco, F. G., and Godinho, L. (2013). "On the use of lightweight mortars for the minimization of impact sound transmission," Construction and Building Materials 45, 184-191. DOI: https://doi.org/10.1016/j.conbuildmat.2013.04.001

Carvalho, P. E. (1998). "Espécies introduzidas alternativas às do gênero Pinus e Eucalyptus para reflorestamento no Centro-sul do Brasil," in: Galvão APM, coordenador. Espécies não tradicionais para plantios com finalidades produtivas e ambientais, Colombo: Embrapa Florestas; pp. 74-99.

Castro, V., and Iwakiri, S. (2014). "Influence of different degrees of acetylation in the 
physical and mechanical properties of particleboards and wood-cement composites," Cerne 20(4), 535-540. DOI: 10.1590/01047760201420041673

Castro, V., Araújo, R. D., Parchen, C., and Iwakiri, S. (2014). "Evaluation of pretreatment effects of Eucalyptus benthamii Maiden \& Cambage wood on the compatibility degree with Portland cement," Revista Árvore 38(5), 935-942. DOI: 10.1590/S0100-67622014000500018

Del Menezzi, C. H. S., Castro, V. G., and Souza, M. R. (2007). "Production and properties of a medium density wood-cement boards produced with oriented strands and silica fume," Maderas, Ciencia y Tecnologia 9(2), 105-115. DOI: 10.4067/S0718-221X2007000200001

Fan, M., Ndikontat, M. K., Zhou, X., and Ngamveng, J. H. (2012). "Cement-bonded composites made from tropical woods: Compatibility of wood and cement," Construction and Building Materials 36, 135-140. DOI:

10.1016/j.conbuildmat.2012.04.089

Faria, C., Chastre, C., Lúcio, V., Nunes, Â. (2013). "Compression behaviour of short columns made from cement-bonded particle board," Construction and Building Materials 40, 60-69. DOI: 10.1016/j.conbuildmat.2012.09.074

Frybort, S., Mauritz, R., Teischinger, A., and Müller, U. (2008). "Cement bonded composites - A mechanical review," BioResources 3(2), 602-626. DOI: 10.15376/biores.3.2.602-626

Garcez, M. R., Santos, T., Garcez, E. O., and Gatto, D. (2016). "Mechanical properties of cement-wood composites with treated Pinus elliottii sawdust," Ciência da Madeira 7(1), 16-27. DOI: 10.12953/2177-6830/rcm.v7n1p16-27

Hamouda, T., Hassanin, A. H., Saba, N., Demirelli, M., Kilic, A., Candan, Z., Jawaid, M. (2019). "Evaluation of mechanical and physical properties of hybrid composites from food packaging and textiles wastes," Journal of Polymers and the Environment 27, 489-497. DOI: 10.1007/s10924-019-01369-3

Higa, A. R., and Prado, C. (1998). “A. Acrocarpus fraxinifolius Wight \& Arn.,” in: Nontraditional species for plentios for productive and environmental purposes, Colombo: Embrapa Florestas, 57-60.

Iwakiri, S., and Prata, J. G. (2008). "Use of Eucalyptus grandis and Eucalyptus dunnii wood in the production of cement-wood panels," Cerne 14(1), 68-74.

Latorraca, J. V. F. (2000). Eucalyptus spp. in the Production of Cement-wood Panels, Ph.D. Dissertation, Universidade Federal do Paraná, Curitiba, Paraná, Brazil.

Latorraca, J. V. F. and Iwakiri, S. (2000). "Effects of Eucalyptus dunnii (Maid) particle treatment, variation of wood-cement ratio and use of additives on the physical and mechanical properties of wood-cement sheets," Cerne 6(1), 68-76.

Latorraca, J. V. F., and Iwakiri, S. (2001). "Effect of the steam cure on the mechanical properties of cement-wood bonded boards," Floresta e Ambiente 8(1), 84-93.

Libor, Z., Zhang, Q., Israel, C., and Mathur, N. D. (2009). "Nanocoatings on micro or nano-particles," Materials Science and Technology 25(11), 1307-1311. DOI: 10.1179/026708309X12474766656173

Miller, D. P., and Moslemi, A. A. (1991). "Wood-cement composites: Effect of model compounds on hydration characteristics and tensile strength," Wood and Fiber Science 23(4), 472-482.

Moslemi, A. A., Garcia, J. F., Hofstrand, A. D. (1983). "Effect of various treatments and additives on wood-Portland cement-water systems," Wood and Fiber Science 15(2), 164-176. 
Moslemi, A. A. (1999). "Emerging technologies in mineral-bonded wood and fiber composites," Adv. Perform. Mater. 6(2), 161-179.

Moslemi, A. A., and Pfister, S. C. (1987). "The influence of cement/wood ratio and type on bending strength and dimensional stability of wood-cement composite panels," Wood and Fiber Science 19(2), 165-175.

Naghizadeh, Z., Faezipour, M., Ebrahimi, G., Hamzeh, Y. (2012). "Manufacture of lignocellulosic fiber-cement boards containing foaming agent," Construction and Building Materials 35, 408-413. DOI: 10.1016/j.conbuildmat.2012.03.007

Pimentel, L. L., Beraldo, A. L., and Savastano, H. (2006). "Durabilidade de compósito biomassa vegetal-cimento modificado por polímero,” Eng. Agrícola 26(2), 344-353. DOI: $10.1590 / \mathrm{S} 0100-69162006000200002$

Prado, C. A., Pereira, J. C. D., Mattos, P. P., and Higa, A. R. (2003). "Physical and chemical characteristics of Acrocarpus fraxinifolius wood," in: Boletim de Pesquisa e Desenvolvimento 14, Colombo: Embrapa Florestas, 1-14.

Sarto, C., and Sansigolo, C. A. (2010). "Kinetics of the removal of Eucalyptus grandis wood extractives during kraft pulping," Acta Scientiarum Technology 32(3), 227-235. DOI: 10.4025/actascitechnol.v32i3.4237

Sheshmani, S., Ashori, A., and Farhani, F. (2012). "Effect of extractives on the performance properties of wood flour-polypropylene composites," Journal of Applied Polymer Science 123, 1563-1567. DOI: 10.1002/app.34745

Silva, J. V. F., Ferreira, B. S., Campos, C. I., Christoforo, A. L., and Lahr, F. A. R. (2016). "Characterization of particleboards produced with Pinus spp. waste," Scientia Forestalis 44(111), 623-628. DOI: 10.18671/scifor.v44n111.08

Silva, J. V. F., Bianchi, N. A., Oliveira, C. A. B., Caraschi, J. C., Souza, A. J. D., Molina, J. C., and Campos, C. I. (2019). "Characterization of composite formed by cement and wheat straw treated with sodium hydroxide," BioResources 14(2), 2472-2479. DOI: 10.15376/biores.14.2.2472-2479

TAPPI T204 (1997). “Solvent extractives of wood and pulp,” TAPPI Press, Atlanta, GA, USA.

Tessaro, A. B., Gonçalves, M. R. F., Gatto, D. A., Pollnow, E. N., Carreño, N. L. V., and Delucis, R. A. (2015). "Cementitious composites strengthened with pure eucalyptus fiber and treated with tetraethyl ortosilicate (TEOS 98\%)," Ambiente Construído 15(3), 47-55. DOI: 10.1590/s1678-86212015000300025

Venturin, N., Carlos, L., Souza, P. A., Macedo, R. L. G., Venturin, R. P., Higashikawa, E. M. (2014). "Silvicultural performance of Acrocarpus fraxinifolius Wight in function of the different spacing and ages," Cerne 20(4), 629-636. DOI: 10.1590/0104776020142004668

Wang, L., Chen, S.S., Tsang, D.C.W., Poon, C.S., Shih, K. (2016). "Value-added recycling of construction waste wood into noise and thermal insulating cementbonded particleboards," Construction and Building Materials 125, 316-325. DOI: 10.1016/j.conbuildmat.2016.08.053

Article submitted: September 21, 2019; Peer review completed: December 21, 2019; Revised version received and accepted: January 16, 2020; Published: January 21, 2020. DOI: 10.15376/biores.15.1.1656-1664 